\title{
Program for prevention of falls among elders: experiences in a Brazilian health plan
}

\begin{abstract}
Quality of life for elders relates to the prevention of many events that may compromise their health. Falls represent a meaningful worry, especially since it can incur in losses on their functional ability. One important factor associated with an increase in fractures among the elderly is the presence of osteoporosis. Preventing and postponing both these problems is of fundamental importance to guaranteeing and maintaining good health among elders. The article presents the results found in a program for fall prevention performed in the city of São Paulo, Brazil, that relates to helping elders find better health security and quality of life.
\end{abstract}

Keywords: falls, elderly, prevention, health care, life quality

\author{
Volume 3 Issue 2 - 2018
}

\author{
Maria Elisa Gonzalez Manso,' Leandro Tadeu \\ Prazeres Maresti, ${ }^{2}$ Andréia Veloso Osti ${ }^{2}$ \\ 'Social Gerontology Program, Brazil \\ ${ }^{2}$ Nursing graduation program, Brazil
}

Correspondence: Maria Elisa G, Manso, Social Gerontology Program, R Celso de A Marques n740 Mooca City São Paulo, State São Paulo, Brazil,Tel +55- I I-99365263 I,

Email mansomeg@hotmail.com

Received: February 25, 2018 | Published: April 24, 2018

\section{Introduction}

The Brazilian health system is characterized by its public access, universal and free to every national citizen, however, private initiative is not forbidden from offering paid health plans or health insurance, being freely marketed and making up what is denominated as the supplementary health sector. These plans are characterized by providing the same coverage of services as the public sector, but are differentiated by having their own hospital network and access to clinics, which varies according to the general income of the user The Brazilian supplementary health sector englobes only $30 \%$ of the national population, concentrated in regions such as the Southeast, the area that agglomerates the richest cities in the country, including São Paulo. ${ }^{1}$

The Brazilian population has been steadily aging. Nowadays, it is estimated that the average Brazilian life expectancy is approximately 75 years, although with a difference between the sexes: the Brazilian woman lives more years than the man. ${ }^{2}$

When we observe the population that buys and utilizes health insurance, the age factor is more pronounced, which can show that growing old in Brazil might be related to income: the higher the income, the more years lived. ${ }^{2}$

Analyzing the demographic characteristics of the elderly associated to the Brazilian supplementary health system, the highest coverage is concentrated among the females and in the Southeast region, as was already mentioned. It is also noteworthy that these people are in the age groups above 70 years, mainly, above 80 , existing insurances that possess $21 \%$ of their client total above such age groups, which commands attention, since in the population Brazilian population as a whole, the total number of elderly people does not exceed $11 \%{ }^{3}$

\section{Discussion}

Health care for the elderly imposes a series of challenges, with the main goal being to maintain their functional capacity. An independent and autonomous elder has better life quality, therefore, a health care program aimed at such populational segment must prioritize the prevention of any worries that may compromise it.
Among these, falling must be highlighted, a very relevant public health problem that can result in serious consequences regarding the life quality of the elderly, as well as causing considerable costs to the health system, the elderly themselves and their families. Falls, among the Brazilian elderly population, are the leading cause of accidents in people over 60 years of age and account for up to $70 \%$ of accidental deaths in people of 75 plus years, and, as people grow even older, falling becomes every time more frequent. ${ }^{4-6}$

The article has as its objective expose the findings obtained by a program of fall prevention among the elderly, performed in the city of São Paulo, Brazil. In said city, starting in 2010, a health insurance program has been developing a program to prevent injuries in a predetermined group of elderly people, all without prior disabilities and residents in the city of São Paulo, being included a special emphasis on the prevention of falls. This program consists of home visits made by nurses, in which the elderly are advised about possible problems in their residence that can cause an eventual fall (such as furniture, stairs, inadequate light, among others) and receive instructions and educational materials on how to prevent such occurrence. In addition to the physical environment, other issues are also addressed by the program, especially the prevention of osteoporosis, a bone disease with a high prevalence among the geriatric population, especially women, and associated with the majority of fall cases in the country.

In order to properly verify the results of said program, a research was carried out in 2016, with a total of 86 elderly women participants, 40 of them being osteoporosis patients (composing the first group and with a mean age of 76.65 years) and the remaining 46 not having said disease (being part of the second group and having a mean age of 77.30 years). In the research, not only results regarding falls among the elderly were accounted for, but were also verified emphasis points that are included in the osteoporosis prevention program, such as adequate sun exposure, and then the two groups were compared. These women were part of the program for five uninterrupted years, all being active participants and all receiving constant medical care, without any calcium or vitamin D supplementation.

In the research, were verified emphasis points for said program, including, the incentive to proper solar exposition, smoking habits, 
incentive to physical activities, body weight reduction and ambient modifications. The examination was performed on the date of inclusion in the program and after the completion of five whole years spent among the group, checking for improvement in the variables afore mentioned and if there were any cases of falls among these elders.

The data was collected through the medical reports of the group and statically analyzed, being that for all the tests were applied a 5\% meaningfulness level. That way, a difference among the groups was considered if $\mathrm{p}$-value was less than 0,05 . For the comparison of the qualitative variables between the groups 1 and 2, it was utilized the chi-squared distribution or, when necessary, the Fisher's exact test. Meanwhile, for the comparison of the quantitative variables, Student's t-test was chosen and the Mann-Whitney $U$ test was used when an analyzed group possessed less than ten patients.

It was observed that there was no statistically significant difference between the groups in the following variables: adequate sun exposure; smoking habit; frequency of physical activity; and body weight. However, when comparing the date of entry into the program and five years later, related to the group of elderly women possessing osteoporosis, there was evidence of significant improvement in all variables, except for smoking habit, showing that there was a lessening in the risk factors associated with osteoporosis in the first group. ${ }^{7,8}$

\section{Conclusion}

With these data, it can be concluded that the program has presented favorable results in stimulating self-care and prevention osteoporosis, although there were falls among both groups. Despite the small number of those, two $(4.3 \%)$ in the group of elderly women without osteoporosis and four (10\%) in the group with the disease, the fact that all occurred at home caused the program to be rethought.

Fall prevention, an event that may be disabling in the elderly, is a challenge to be faced. In Brazil, most of these occur at home, which makes their prevention a little more difficult. Establishing prevention programs aimed at self-care and health education, with environmental interventions included is a difficult task, but one that must be answered.

The small number of people enrolled in the program described here compared to the total number of elderly people in the Brazilian population, should be highlighted as a limitation for such study, which means that these findings must not be completely generalized.

\section{Acknowledgements}

None.

\section{Conflict of interest}

Authors declare no conflicts of interest with this manuscript.

\section{References}

1. http://www.ans.gov.br/aans/quem-somos.

2. http://www.ibge.gov.br/home/estatistica/populacao/condicaodevida/ indicadoresminimos/sinteseindicsociais2010/SIS_2010.pdf

3. Leite F. Envelhecimento populacional e a composição etária de beneficiários de planos de saúde. São Paulo, IESS, 2011.

4. Siqueira FV, Fachinni LA, Piccini RX, et al. Prevalência de quedas em idosos e fatores associados. Revista de Saúde Pública. 2007;41(5):749 756.

5. http://www.projetodiretrizes.org.br/projeto_diretrizes/082.pdf.

6. World Health Organization. Global Report on Falls Prevention in Older Age. França, WHO Library, 2007.

7. http://www.who.int/ageing/publications/Falls_prevention7March.pdf

8. Faisal CA, Zacchello KP. Osteoporosis: Prevalence and Risk Factors among $>49$ Year-Old Women in Private Practice Environment. Acta Ortop Bras. 2007;15(3):146-150. 